\title{
Audácia de sonhar: memória e subjetividade em Luce Fabri
}

\author{
Margareth Rago*
}

"O anarquismo é mais um caminho do que um fim, a finalidade é sempre inalcançável, qualquer finalidade, nós a concebemos como inteira, perfeita e como tal não se alcança. Sacrificar a essa finalidade o que a pessoa sente e pensa é suicida, porque, na realidade, não se consegue nada, tampouco no momento presente e o que interessa é o presente que estamos vivendo, que é o que existe. $O$ anarquismo é uma forma de sentir o presente em vista de algo, em vista de uma finalidade, quer dizer senti-lo libertariamente, em vista de uma liberdade, pois o perfeito não existe, porém, podese ir a ele... Não é uma atitude individual, mas social, que interessa à sociedade em seu conjunto, portanto implica organização, ordem, razão..."

Foi ESTA A DEFINIÇÃO DE ANARQUiSMO que me deu a militante italiana Luce Fabbri, logo que iniciamos nossas conversas em 1995, e considero-a uma porta de entrada bastante esclarecedora para iniciar este artigo, que explora os caminhos políticos e subjetivos construídos por esta militante libertária a partir de suas memórias.

Nosso primeiro encontro havia ocorrido em 1992, já em seus 84 anos de idade e, nessa ocasião, fui tomada pelo sentimento de que deveria

* Professora do Departamento de História da UNICAMP. 
agir rapidamente no sentido de colher seus depoimentos, gravar suas memórias, talvez escrever sua biografia - preservar, enfim, todo um passado ameaçado pelo esquecimento. Romântica ou não, queria ouvir as muitas estórias daquela militante - mulher e anarquista -, que havia sobrevivido ao século, tendo nascido em 1908, em Roma. Queria saber como uma socialista libertária havia lutado contra os macro e os micro-poderes, contra o fascismo italiano e a ditadura militar no Uruguai dos anos setenta, como havia construído seus espaços de autonomia nos meios políticos, acadêmicos e familiares, tanto em se tratando das relações de gênero, quanto das de classe, ao longo de sua vida. Como, enfim, havia conseguido driblar as dificuldades do mundo e preservar-se de tal maneira que eu a encontrava, nos últimos anos de sua vida, tão jovial e mentalmente ágil, crítica incansável da atualidade e anarquista convicta. Decidi, então, apresentá-la ao mundo e contribuir para subverter toda uma tradição misógina que exclui as mulheres da memória coletiva e que justifica essa exclusão afirmando que elas nada produziram.

Naquela época, ainda não sabia que Luce se formara em Letras pela Universidade de Bolonha, na Itália, em 1928, onde fora aluna do filósofo socialista Rodolfo Mondolfo, que eu conhecera na adolescência através de seu famoso livro intitulado O Pensamento Antigo; também desconhecia que trabalhara até a década de 1990 como crítica literária e como professora de Literatura Italiana na Universidade da República do Uruguai, país onde se refugiara, desde 1929, ao fugir da violência fascista; ignorava completamente sua extensa e multifacetada produção intelectual e política ${ }^{1}$.

Minha admiração por ela cresceu com as muitas descobertas que se sucederam ao longo dos momentos em pude desfrutar de seu convívio e entrevistá-la em Montevidéu, ao mesmo tempo em que percorria seus inúmeros textos políticos, literários e históricos, cuidadosamente guardados nas prateleiras de sua ampla e diversificada biblioteca ${ }^{2}$.

1 Em se considerando o volume de sua produção política, filosófica, literária, histórica e pedagógica, citarei, na bibliografia, apenas os trabalhos que aparecem nesse texto. Para maiores informações, veja-se Rago, 2001.

2 O resultado deste trabalho foi publicado como Entre a História e a Liberdade: Luce Fabbri e o anarquismo contemporâneo, Editora da Unesp, 2001. 
Pus-me a gravar as estórias que ela passou a contar, inicialmente em seu escritório, diante das fotos do pai, o anarquista Luigi Fabbri e de seu mentor Errico Malatesta e, nos últimos anos, com maior dificuldade de locomoção, no sofá de seu amplo quarto, onde as mulheres da família, entre as quais a avó Emília e a mãe Bianca, nos espreitavam das fotografias amareladas penduradas na parede. Seus comentários sobre essas imagens, feitas em 1914, na Itália, foram respostas às perguntas que me preparava para fazer: "Foram feitas por tio Bruno, irmão de minha mãe, apaixonado por fotografia. A arte da fotografia estava em seus inícios... Passamos dois meses lindos... em Porto Ricanati, no Adriático, na parte norte, em uma casa de praia, durante as férias, antes da guerra... Era um porto de pescadores, todas as noites chegavam em seus barcos de pesca..."

Ora falando em espanhol, ora em italiano, suas lembranças focalizaram momentos singulares de sua vida pessoal e acontecimentos que marcaram o século 20 e a sua própria experiência como militante anarquista. Aos poucos, seus depoimentos, as recordações evocadas, o desfile de personagens entre companheiros/as, amigos/as, familiares e inimigos políticos foram compondo oralmente uma autobiografia, indo desde as recordações da infância passada entre Roma e Bolonha, ao exílio forçado em Paris e posteriormente no Uruguai, onde desembarcou depois de uma longa viagem clandestina e onde viveu por mais de setenta anos.

Todo um século desfilou aos meus olhos nesse trabalho minucioso e labiríntico de investigação da memória de Luce, ou nessa viagem em que ela me conduziu através dos tempos vividos de sua infância e adolescência até a morte, em 19 de agosto de 2000.

Descobri progressivamente que nossas afinidades iam muito além da ideologia política, pois suas recordações do passado me abriam as portas para conhecer mais detidamente e de uma maneira muito rica a tradição italiana da qual eu também faço parte, mas que por algum motivo mantive à margem em minha formação intelectual. Não eram apenas as portas da cidade de Montevidéu e da vida cotidiana dos anarquistas, num plano internacional, que se abriam para mim. Com seus relatos, as ruínas e os sons das ruas de Roma, as casas avermelhadas e as arcadas nas calçadas de Bolonha, a universidade mais antiga da Europa, os poetas, como Leopardi, Carducci e Montale, artistas e filósofos 
italianos de vários séculos, inúmeras figuras do anarquismo e de outras tendências políticas, entre mulheres e homens, enfim, muitos acontecimentos e personagens passaram a fazer parte do meu próprio arquivo.

O contato com essa senhora erudita e reflexiva, profundamente aberta à vida, fez-me inevitavelmente pensar na utilidade da história, na importância da preservação da memória, sobretudo daquela silenciada pelos jogos do poder e, mais ainda, levou-me a valorizar os aportes da história oral, área em que havia incursionado timidamente em outra ocasião. A re-apresentação oral do passado, "fazendo emergir do tempo/experiência os fatos considerados mais significativos do ponto de vista do narrador" (Guimarães Neto, 2000, p. 99) traz coloridos, cheiros e emoções que dificilmente se encontrariam no texto histórico, na maior parte das vezes muito asséptico em sua pretensão de objetividade.

Em relação à utilidade da História, aposto na idéia de que é necessário ampliar o repertório das experiências positivas de que dispomos, sobretudo daquelas que foram construídas no sentido de impulsionar a liberdade, potencializar as iniciativas libertárias, construir redes de solidariedade, abrir espaços de resistência à dominação social e política. Inquieta-me profundamente perceber que a memória da guerra, ou seja, das experiências de destruição e morte e dos homens que as promoveram revela-se sempre muito mais poderosa do que a da paz, e nesse sentido quero dizer que muitos conhecem Darwin e a teoria da evolução das espécies, mas desconhecem seu crítico e contemporâneo, o anarquista Pedro Kropotkin, autor de A Ajuda Mútua; do mesmo modo, muitos sabem quem foi Benito Mussolini, mas desconhecem Malatesta, tido como o "Lênin da Itália", nos anos vinte.

Poderia acrescentar, na mesma direção, que a história no feminino apenas começa a evidenciar a dimensão masculina ou falocêntrica da grande narrativa da história, como apontam as feministas. Daí, a própria idéia de realizar esse trabalho de preservação das memórias de Luce, considerada também como "cronista de uma genealogia anarcofeminista" (Greene, 1997).

Depois de percebermos a pluralidade do passado, as múltiplas temporalidades constitutivas dos processos sociais e culturais, os silêncios, os esquecimentos e as implicações políticas da exclusão operada pela memória histórica, entendida como discurso dos dominantes, foi 
inevitável o sentimento benjaminiano de que a tarefa premente do historiador é a de salvar a memória, livrando-a do esquecimento. Este mesmo sentimento, talvez romântico e ingênuo, tem sido em grande parte responsável pela importância e popularidade que a história oral ganhou nas últimas décadas, já que todos ou quase todos os grupos sociais buscam inscrever-se no mapa, desejosos de terem suas experiências cartografadas, honradas ou vingadas na História. De certo modo, se de um lado o passado perde importância no mundo pós-moderno, como argumenta o historiador norte-americano David Harlan (1997), a ponto de muitos críticos e teóricos da atualidade escreverem livros e livros sem a necessidade de um profundo conhecimento histórico, de outro, amplia-se o leque dos grupos sociais, étnicos, sexuais, das famílias e dos indivíduos que reivindicam seu "direito à história", como observa Pierre Nora.

Nessa direção, talvez seja melhor ouvir a própria Luce, com todo o seu olhar muito perspicaz de mulher estrangeira e que viveu literalmente entre fronteiras, entre "o exílio e a imigração", como ela mesma diz, refletindo sobre o tema. Num depoimento gravado em julho de 1997, afirma:

"Nossos vínculos com o passado são muito fortes e sobretudo são fortes a nível coletivo, e uma ruptura drástica com o passado, completa, só se pode fazer à custa da liberdade, só oprimindo e forçando as vontades. Há algo na tradição que oprime, porém há uma continuidade que não se pode romper violentamente, só se pode deixar cair, provocar a queda do que está sobrando, das folhas secas, do que já não tem vida... Porém, uma mudança libertária deve passar pela vontade coletiva, a vontade coletiva sempre tem em conta a história... mesmo que inconscientemente... Conhecer a história tem um valor vital, um valor de reconsideração dos valores tradicionais e é uma forma, um veículo de transformação enquanto se criticam os valores à medida que se conhece..."

Em se tratando das grandes contribuições e possibilidades abertas pela história oral, gostaria de lembrar algumas questões discutidas por autores conhecidos, como Paul Ricoeur. Ao refletir sobre as relações 
entre a história e a memória, na esteira dos questionamentos de Jacques Derrida sobre o privilégio conferido à palavra escrita, ao contrário da oral, em nossa tradição de pensamento, este aponta para a tensão aí existente entre um apelo que pesa em favor da primeira e um outro que beneficia a segunda. Trata-se, de um lado, de uma postura que privilegia a "história da memória", fazendo supor que esta se constituiu em "novo objeto" da história, assim como o corpo, a sexualidade, a alimentação; de outro, de uma posição inversa, que postula a "historicização da memória", em que a história tem como tarefa ajudar a corrigir e a ampliar a memória, fazendo com que esta entre em contato com dimensões mais profundas de si mesma e se conheça melhor. Neste caso, a história estaria a serviço da memória, ao contrário do caso anterior em que a memória se subordinaria à história como seu objeto (Ricoeur, 2000, p. 175).

Refletindo sobre a minha experiência particular de historiadora no contato com o trabalho da memória de Luce Fabbri, sobretudo em depoimentos orais, entendo que não busquei trazer a "realidade" de seu passado, como se tivesse um olhar neutro capaz de organizar "de fora" e "do alto" as experiências que me foram paulatinamente apresentadas, nem tomei seus relatos como reflexos da realidade. Antes, tive em vista trabalhar a construção de sua narrativa do passado, considerando seus depoimentos orais como práticas discursivas, na concepção de Michel Foucault (1986), e procurei perceber a produção de sua subjetividade ao narrar a própria vida.

Portanto, estive atenta à fina estruturação temporal e temática com que Luce organizou suas recordações, selecionando as que lhe pareciam mais valiosas, compondo quadros bastante vivos e valorativos do universo cultural e político do anarquismo e, ao mesmo tempo, tomando uma referência identitária de anarquista como norte para sua construção do passado. Vale lembrar, ainda, que eu mesma a procurei por ser uma militante libertária e que foi a partir desse eixo que me interessei por sua maneira de ser, por suas idéias e vivências. Perguntava-me como havia sido a experiência de ser libertária e mulher para Luce Fabbri. Como ela havia entendido e praticado esta utopia desde o cotidiano?

Sem dúvida, a identidade de anarquista organiza e estrutura sua elaboração do passado pessoal e da experiência coletiva. Filha do militante anarquista Luigi Fabbri, discípulo e biógrafo de Malatesta, e tendo 
convivido desde cedo com as lutas sociais da Itália dos anos 1910 e 1920, tendo participado da resistência anti-fascista no exílio e dedicado-se a lutar pelas idéias libertárias até o fim, suas memórias giram em torno de experiências políticas e sociais cruciais - como a ascensão do fascismo e a destruição violenta das cooperativas de produção e consumo em Bolonha, ou ainda as conquistas e derrotas da Revolução Espanhola, os anos da ditadura militar no Uruguai - ao narrar episódios que remetem à esfera pública ou privada. É assim que inicia o relato de sua vida, pelo nascimento no interior de uma família já praticante das idéias libertárias:

"Tive uma educação libertária desde o primeiro momento... Em um período em que se enfaixavam as crianças como se fossem múmias egípcias. Não conheci as faixas... as outras mulheres diziam para a minha mãe que eu iria me quebrar, que era perigosíssimo [ficar sem faixa]... Nesse sentido, já crescemos num meio bastante moderno, sem que fosse particularmente moderna a intenção..."

Num outro momento, Luce traz a impactante presença do líder anarquista Malatesta, marcando muito cedo sua vida, entrecruzada com as lutas políticas do período. Recorda-se que, em 1913, aos 5 anos de idade, viu chegar, na casa dos avós, "aquele homem de olhar penetrante”, amigo de seu pai, que viera visitá-la. Como a enérgica avó se pusesse a repreendê-la pelas brincadeiras esfuziantes que fazia no jardim, o militante resolveu interferir, defendendo a liberdade infantil, dizendo-lhe "que lhe parecia que eu tinha que ser livre, movimentar as pernas e os braços como quisesse, tinha 5 anos! Minha avó retrucou que tinha que educar-me e que portanto... Essa discussão entre minha avó e Malatesta ficou gravada em mim e me causou uma impressão enorme, porque ninguém ousava discutir com minha avó e esse homenzinho que se atrevia e que dizia coisas tão interessantes, ficou gravada em mim... Essa é a primeira visão que tenho de Malatesta. Depois ele se foi para Londres, o exílio..."

A dimensão mitológica da figura de Malatesta é atribuída, em suas lembranças, à imaginação fantasiosa da criança; no entanto, suas memórias também fazem emergir um homem simples e delicado, sempre muito querido, habilidoso, capaz de articular politicamente os adultos, 
tanto quanto de brincar despreocupadamente com as crianças. O afeto em relação a ele é profundamente marcado em seus relatos:

"E recordo que se falava muito de Malatesta em casa, Errico Malatesta! Ele estava em Londres, nós éramos crianças e ouvíamos falar deste personagem remoto... Em seguida, depois da guerra, meu pai estava esperando que Malatesta voltasse, o governo italiano não queria recebê-lo e pressionava para que o governo inglês não o deixasse sair. Para nós essa história de Errico que tinha que chegar, porém que dois governos se opunham a que viesse... era uma história romântica..."

Aliás, seu primeiro artigo, "Ciência, Filosofia e Anarquia", escrito aos 17 anos de idade e publicado na revista libertária Pensiero e Volontá, polemiza com Malatesta em relação à maneira como ele e Kropotkin definem esta doutrina (Fabri, 1925). Em nossas conversas, em janeiro de 1996, Luce ri ao lembrar-se do pseudônimo que utilizou para assinar o artigo polêmico de 1925:

"O pseudônimo que usei é Epicari, nome de uma escrava romana que participa da conspiração contra Nero, no primeiro Império romano. Deixou-se torturar sem denunciar e a mataram. Bem, foi idealizada como merece, por outro lado!"

Vale atentar, o que ela mesmo faz nos depoimentos em que relê o passado, para a dimensão política e rebelde da personagem sob a qual se coloca, ou se protege, já em seu primeiro texto. Do mesmo modo, é possível dizer que a principal estratégia de produção de seu discurso é a de colocar-se no espaço da política para falar do passado, tanto quanto para pensar as questões da atualidade.

Nesse sentido, a emergência do fascismo é um tema privilegiado em suas memórias, sobre o qual, aliás, escreve Camisas Negras, livro publicado em 1933, pois vivendo num meio anarquista pôde acompanhar de dentro a violência na luta que os fascistas empreenderam contra o movimento social. Como conta em depoimento gravado em fevereiro de 1995, já no final dos anos 1910, quando passou a ter um contato mais direto com colegas da classe média, ao cursar o secundário numa escola mais central de Bolonha: 
"Toda a classe média italiana, nesse momento, era bastante reacionária, eu me encontrei num mundo totalmente distinto, minhas companheiras tinham costumes totalmente diferentes... Foi uma mudança muito grande para mim... Ademais desde cedo, nesse ambiente de classe média, assisti à incubação do fascismo. Bolonha era o berço do fascismo, foi fundado em Milão, porém se incubou em Bolonha, nos ambientes agrários, entre os proprietários de terra, o campesinato não-proprietário era quase todo socialista, e os agrários financiavam as bandas fascistas contra as cooperativas, na primeira fase do fascismo.

Bem, não sei o que pode interessar, há muitas coisas. Foram anos em que parecia muito perto uma revolução na Itália, o movimento anarquista conheceu um fortalecimento e um dinamismo muito especial, teve um jornal - o Umanitá Nova - por uns anos... Meu pai mandava um manuscrito, todos os dias o acompanhava ao correio, íamos ao centro... Foi um período de atividade muito intensa da parte dele, de grandes esperanças, depois ele foi dos primeiros a começar a vislumbrar o desastre... Meu pai fora atacado nas ruas, me chamaram em casa, a vida se fez bastante difícil e houve um momento depois quando o fascismo começou a se consolidar, se estabeleceu o juramento de fidelidade ao regime para os professores, meu pai se negou a jurar, então cruzou a fronteira para a França, eu fiquei só e terminei minha carreira..."

Os temas do âmbito do privado são, em certa medida, secundarizados em suas preocupações, pois aparecem mesclados com as recordações dos acontecimentos políticos e sociais. As relações amorosas, o casamento e a maternidade são aspectos de sua vida que entram com menor destaque nesse trabalho da memória, que privilegia os momentos da resistência política ao fascismo, das lutas sociais na Espanha e na América do Sul, de trabalho com os "companheiros", ou de enfrentamentos com a repressão.

É o caso dos momentos revolucionários da Guerra Civil Espanhola, que aparecem, em suas recordações, justapostos ao seu casamento com 
o anarquista italiano Ermácora Cressatti, nesse ano de 1936. Definido como "os dias mais lindos de minha vida", dificilmente se pode saber o que Luce privilegia em seu coração:

"E então as duas coisas vieram juntas: o casamento, a Revolução espanhola, a casa nova... Em seguida, vieram as férias de verão e durante todo o verão, não fizemos nada mais que trabalhar pela Espanha."

O que ela enfatiza, mesmo ao relatar esse momento de união conjugal tão marcante em sua vida pessoal, é o forte envolvimento com os acontecimentos revolucionários efervescentes na Espanha, diluindo assim os sentimentos e emoções trazidos pelo casamento. A militante, portanto, sobrepõe-se à figura da esposa e da amante em sua narrativa:

"Foram três anos em que vivemos mais na Espanha do que aqui, com o coração...”, lembra Luce com a expressão esfuziante, "na realidade, tudo o mais havia desaparecido. Quando fui a Barcelona em 1981, parecia que estava em casa... Conhecia Pedralbes... Todos esses nomes, ademais ali estava a memória de Francisco Ferrer... Me levaran a Monjuic... para ver a fortaleza, a prisão, havia uma cela onde Ferrer havia sido encarcerado..."

Convidada pela anarquista espanhola Federica Montseny - que se tornou Ministra da Saúde no governo de Largo Caballero - para trabalhar nas escolas dos sindicatos ligados à CNT - Confederação Nacional do Trabalho - naquela cidade, Luce decide ficar em Montevidéu. Mesmo assim, acompanha cotidianamente os acontecimentos surpreendentes que agitavam aquele país, compilando as notícias, juntando informações, selecionando textos que lhe eram enviados pelos companheiros que ali lutavam. Esse trabalho resulta no livro 19 de Julio, coletânea de documentos publicados imediatamente sob o pseudônimo de Luz D. Alba:

"Através da Revolução Espanhola, vivemos essas jornadas, lemos os relatos linha por linha, o ano de 1936 foi de grande esperança e de grande emoção... De repente, essa resistência de todo um povo, tão esperada, tão total, esse dar-se a si sem pensar... Tínhamos a sensação de que o fascismo não era tão poderoso como parecia e... de que podia ser vencido... Foi uma emoção tão grande e, depois, chegavam 
os boletins da CNT-FAI, com as notícias miúdas, esse povo que havia coletivizado toda a economia... Nos reunimos, mandamos delegados para Barcelona... De outro povoado, chegavam delegados com notícias semelhantes... Era algo maravilhoso, claro, além disso, há todo o aspecto ético da resistência contra o fascismo, das milícias que se reuniam e partiam para a frente de Aragão, que lutavam com tanques improvisados, tinham uma força arrasadora... Essa criatividade capilar... porque não era um sistema que se estabelecia não, era todo um povo que estava criando algo novo... Foi um verdadeiro milagre, tivemos a sensação de milagre..."

Portanto, Luce opta deliberadamente por não dar visibilidade a momentos que considera íntimos de sua vida pessoal, pois acredita que importa para a construção da biografia de uma anarquista muito mais o lado público da militante, da escritora e da intelectual. Na prática, isto significa que muitas vezes não entendia o porquê de minha insistência em ler suas cartas, ou em ver as velhas fotos guardadas nas gavetas, além de discordar de muitas das minhas interpretações, especialmente as relativas às questões de gênero.

Nessa direção, é interessante observar a posição paradoxal que Luce adota em relação ao feminismo e a relativa dificuldade que tem para discutir e assumir as desigualdades nas diferenciações de gênero. Porque embora seu olhar esteja bastante atento para tirar do esquecimento e incorporar em seu relato do passado inúmeras figuras femininas, entre anarquistas, como Débora Céspedes, Esperança, Inês Guida, militantes de sua geração, ou ainda intelectuais, amigas e parentes, ela mesma não percebe esta prática como feminista. Aliás, nem mesmo sei se Luce presta atenção na grande quantidade de mulheres inteligentes e ativas que entram em suas memórias. Além do mais, constantemente criticou minha insistente defesa da importância de escrever a biografia de uma mulher libertária e não de um homem, questionando que o olhar feminino pudesse captar dimensões do cotidiano ou do domínio das emoções e dos sentimentos que, em geral, escapam aos homens, como eu afirmava.

Essas posições, contudo, não a impediram de fazer afirmações contrárias, por exemplo ao avaliar que: 
"As mulheres têm algo de seu para dar, algo de gênero, uma experiência única de uma economia não competitiva: a economia doméstica, em que as crianças têm precedência, em que os velhos estão assistidos porque são velhos, em que cada um dá o que pode e consome o que necessita, isto é a economia doméstica.

Nos últimos tempos, tenho pensado que vale a pena ocupar-se com o problema da mulher, sobretudo nesse sentido. Houve uma revolução, uma integração maciça na vida de relações, à vida pública. Se se conseguisse que a mulher trouxesse essa experiência secular e essa mentalidade... pois ela teve a sorte de não haver sido soldado, ministro ou presidente, com algumas exceções..."

Para ela, portanto, as mulheres podem revolucionar o mundo masculino, se não imitam aos homens, já que são portadoras de uma cultura própria, de outras formas de percepção, de organização e de elaboração prática, estética e mental. Além disso, estiveram na base dos movimentos de resistência às ditaduras latino-americanas, lembra ela: "A participação das mulheres estava dada muito nas bases, elas decidiam quem ia administrar o movimento, tinham participação nas decisões."

Em outro momento, Luce insiste na denúncia da discriminação contra as mulheres pelo fascismo italiano:

"O fascismo estabeleceu por lei que nos últimos anos do ensino secundário não poderiam ser mulheres as professoras de História e Filosofia, porque as mulheres não podiam formar personalidades fortes. Assim, todas as professoras de História e Filosofia não sabiam aonde ir porque não havia Filosofia no primeiro ciclo, enquanto as de História foram ensinar Italiano, Latim, Grego, História e Geografia, nos primeiros anos. As de Filosofia mudaram de matéria, simplesmente. Esta foi uma discriminação que vi a posteriori, porque antes não era assim."

Contudo, os limites de seu questionamento feminista são dados ao adentrar no universo anarquista. Vinda desta tradição política, os conflitos entre as classes e a luta político-ideológica contra a ditadura 
assumem primazia em relação às questões do feminismo. E se em seus diversos artigos e entrevistas recentes, passa a valorizar de forma mais efetiva a cultura feminina, em nenhum momento de suas memórias refere-se a conflitos nas relações de gênero entre os anarquistas, o que certamente deve ter presenciado. Ao contrário, afirma que suas constatações sobre o machismo foram pautadas mais pelo que assistiu fora dos meios libertários do que dentro, o que sem dúvida comporta uma idealização muito grande, ou uma grande preocupação em não macular o anarquismo.

Com uma posição tão definida na leitura do passado e na construção de sua identidade pública, espantei-me ao descobrir o lado mais subjetivo, feminino e emocional de Luce, no livro de poesias que publicou em 1932, intitulado I Canti dell'Attesa. Evidentemente, encontrei suas poesias quando a pesquisa já estava adiantada, meio que por acaso, entre suas coisas, e, logo, ela se esquivou, relutante em falar sobre este "trabalho de juventude":

"Porque era um livro de versos muito militantes, foi publicado em 1932, com a produção anterior, a produção dos 20 anos - I Canti dell'Attesa - 'Os Cantos da Espera' - era a espera de voltar para a Itália, era o exílio, são poemas do exílio, mas muito pouco maduros literariamente, muito tradicionalistas na forma. Para mim, conservam validade, porém nunca os cito, aí está, mas evidentemente (a poesia) não era o meu caminho, este aspecto é só para minha satisfação pessoal..."

Os poemas contrastam fortemente com a narrativa de si construída nos depoimentos, ao mostrarem suas fragilidades, ao darem vazão às suas angústias, tristezas, sentimentos de perda, dor e desamparo, como aparece em Mamma, dammi la mano ("Mamãe, me dê a mão"):

Mamma, son tanto stanca, / son tanto stanca e voglio riposare;/ gli occhi che molto han visto / Son tanto nauseati di guardare. I Che m'importa del mondo? Sono stanca. I Il mio cervello non vuol piú pensare.(...) / Non trovo piú nel cuore la speranza, Non trovo piú l'audacia di sognare. / Che m'importa il lavoro, l'ideale, / che m'importa l'amore? / Mamma, so stanca, ho sonno, mi fa male / tutto quello che vive e che si muove.(...) 
Mamãe, estou muito cansada / Estou muito cansada e quero descansar; / Os olhos que viram muito / Estão muito cansados de olhar. / Que me importa o mundo? Estou cansada. / Meu cérebro não quer mais pensar.(...) / Não encontro mais esperança em meu coração, / não encontro mais $a$ audácia de sonhar / Que me importa o mundo, o ideal, / Que me importa o amor? / Mamãe, estou cansada, tenho sono, me machuca / Tudo o que vive e que se move. (...)

Ou então nas comparações entre a terra natal e o país do exílio. Se Montevidéu é vista como a cidade "oásis" que a recebe "de braços abertos", dimensão exaltada em todos os depoimentos, na poesia não pode substituir a "terra mãe", nem mesmo no inverno, como aparece em Neve di primavera, poema de 1929:

Montevideo, son belle le tue rose / Che cadendo m'invitano a sognare / immagini imprecise e vaporose, / forme vane d'um van fantasticare / Ma il mio cuore resto sotto la neve / gélida, che fa i semi germogliare.

Montevidéu, são belas as tuas rosas / Que caindo me convidam a sonhar / com imagens imprecisas e vaporosas, / formas vãs de um vão imaginar. / Mas, meu coração sob a neve gelada ficou, / sob a neve, que faz as sementes germinarem.

Em L’Esilio, ela reafirma esse sentimento:

E poi tornai nella cittá del sogno / quella ch'amo fra tutte le città. (...) / Ho nel cuore, Bologna, il tuo sorriso / di quando il sol riposa / sui muri Rossi delle case antiche, (...) Or mi separan dalla mia Bologna, / il mar che vien qui a frangersi sul lito, / e ancora terra e ancor dell'altro mare.

E depois voltei à cidade do sonho / aquela que mais amo dentre todas as cidades.(...) / Guardo no coração, Bolonha, o teu sorriso / do momento em que o sol descansa / sobre os muros vermelhos das casas antigas, / (...) Agora me separam da minha Bolonha / O mar que vem aqui bater na praia / E mais a terra e ainda outro mar. 
Toda essa vasta produção intelectual e poética permite, pois, conhecer de modos muito diferenciados a Luce que traz, nos relatos orais, sua própria vida. Apesar da construção racionalizada de seu passado, da preocupação em ordenar temporalmente suas experiências vividas, dando-lhes o sentido que lhe parece o mais importante, a riqueza dos depoimentos possibilita perceber a figura terna e delicada, sensível e amorosa que se esconde atrás da figura pública da militante anarquista, forte, convicta e profundamente engajada nas lutas sociais do passado e do presente. Pois, afinal, todo esse trabalho da memória só faz sentido, para ela, por sua dimensão pública e política, já que se trata de produzir uma nova história do anarquismo e das lutas sociais ao longo do século 20. Uma nova história, pois contada no feminino e por alguém que viveu muito de dentro os acontecimentos do século 20 e que soube, graças a uma sólida formação intelectual, refletir sobre eles.

Toda sua preocupação está direcionada para desfazer os mitos de incompreensão política, de falta de reflexão filosófica, de ingenuidade romântica atribuída aos anarquistas na luta política com os comunistas e liberais, ou seja, para "salvar" o anarquismo, trazendo a riqueza de suas histórias e a grandeza de seus princípios. Além disso, indiretamente, sua contribuição vai muito além, pois volta-se para a defesa das próprias mulheres, ao contrapor-se às idéias elaboradas sobretudo pelo pensamento social do século 19, definindo-as como incapazes e inadequadas para o mundo público. Sua experiência de vida, assim como sua produção intelectual, por si só, atestam a grande contribuição das mulheres às transformações positivas em nosso mundo.

\section{Referências bibliográficas}

ALBA, Luz D. (pseudônimo de Luce Fabbri). 19 de Julio. Antologia de la Revolución Española. Montevidéu, Col. Esfuerzo, 1937.

FABBRI, Luce. I Canti dell'Attesa. Montevideo, M. O. Bertani Editore, 1932. . Camisas Negras. Buenos Aires, Ediciones Nervio, 1935.

FOUCAULT, Michel. A arqueologia do Saber. Rio de Janeiro, Forense Universitória, 1986.

GREENE, Patrícia. "Federica Montseny: Chronicler of an Anarcho-Feminist Genealogy". In: Letras Peninsulares, Fall 1997. Department of Spanish, Davidson College. 
GUIMARÃES NETO, Regina Beatriz. "Artes da Memória, Fontes Orais e Relato Histórico". In: Revista História \& Perspectivas 23. Uberlândia, jul-dez/2000, p. 99-114.

HARLAN, David. The Degradation of American History. Chicago, The Chicago University Press, 1997.

LE GOFF, Jacques. "Memória". In: Enciclopédia Einaudi. Imprensa Nacional/ Casa da Moeda, 1984.

NORA, Pierre. "Entre Mémoire et Histoire. La problématique des lieux". In: Les lieux de la Mémoire. Paris, Gallimard, 1984.

RAGO, Margareth. Entre a História e a Liberdade: Luce Fabbri e o Anarquismo Contemporâneo. São Paulo, Editora da Unesp, 2001.

RICOEUR, Paul. La Mémoire, L'Histoire, L'Oubli. Paris, Seuil, 2000.

Resumo: Este artigo focaliza as dimensões políticas e subjetivas dos depoimentos orais da militante anarquista italiana Luce Fabbri (1908-2000), gravados em Montevidéu, entre 1995 e o ano de sua morte. Trabalhando com os relatos de uma mulher bastante intelectualizada, professora universitária de Literatura Italiana e, ao mesmo tempo, voltada para o meio operário, onde militou desde sempre, destaco alguns momentos históricos relevantes de suas recordações, apontando para o imbricamento das memórias do mundo público e do privado na construção de sua própria subjetividade e na lembrança do passado.

Palavras-chave: anarquismo; memória; história oral; relações de gênero; subjetividade; feminismo.

Dare to Dream: Memory and Subjectivity in Lucce Fabri

ABstract: This article focuses on the public and subjective dimension of the oral narratives produced by Italian anarchist Luce Fabbri (1908-2000), recorded in Montevideo from 1995 until her death. Examining the oral testimonies of this cultivated woman, professor of Italian Literature and at the same time integrated in the workers' world, I highlight the historical relevant moments of her memories of the public and private sphere, pointing to the way they are connected to each other and affect the construction of her own subjectivity as well as the remembering of the past.

KEYWORDS: anarchism; memory; oral history; gender relations; subjectivity; feminism. 